\title{
AN UNUSUAL CASE OF CORNEAL DISEASE
}

BY

\section{F. A. Williamson-Noble}

LONDON

-THE pathology of corneal dystrophies is not yet fully understood, and as the following case presents some points of interest, it was thought worth while to report it, particularly as the notes go back to the time before the disease developed.

The patient, a female domestic aged 44 years, was first seen as a refraction case at the Central London Ophthalmic Hospital in October, 1924. Under homatropine and cocaine the right eye with +1.0 D.sph. +1.0 D.cyl. $180^{\circ}$ read $6 / 9$ and the left with +1.5 D.sph. +1.0 cyl. $180^{\circ}$ read $6 / 6$ partly. She attended again in April, 1927, complaining that she saw a mist now and again with the left eye. Nothing abnormal was found in the eye, her refraction was practically unaltered and her vision the same as before. In November of the same year she complained of seeing a spider's web round lights with the left eye; she was seen on this occasion by the house surgeon and no further note was made except that vision had gone down to $6 / 18$ with correction. I had an opportunity of examining her at her next visit, early in. December when the slit-lamp showed a slight opacity occupying the pupillary area in the posterior third of the cornea. There were no traces of inflammation, no bedewing, no vascularisation or ciliary flush, no keratic precipitates or particles in the aqueous and no iris adhesions, also there was no sign of corneal anaesthesia. The Wassermann reaction was negative and no focus of infection could be found in the teeth, tonsils, nasopharynx or accessory sinuses. The vision was now less than 6/60 and the condition appeared to be some obscure dystrophic process which might quite reasonably be expected to attack the other eye. It was difficult to know what treatment to adopt in order to avoid this, and I had to proceed on what were rather empirical lines.

Three possible explanations occurred to me for the condition : (1) That it might represent the result of endocrine disturbance. (2) That it might be a deficiency disease-on the lines of keratomalacia. (3) That it was due to some defect in calcium metabolism. The patient was therefore put on to thyroid and parathyroid and given cod-liver oil and artificial sunlight treatment. Under this régime the right cornea remained clear and in March, 1928, she thought that the sight of the left eye was a little better though it was still less than 6/60. By the end of April, the disc of opacity in the posterior layers of the cornea was about the size of the undilated pupil, but mydriasis did not seem to improve vision. 


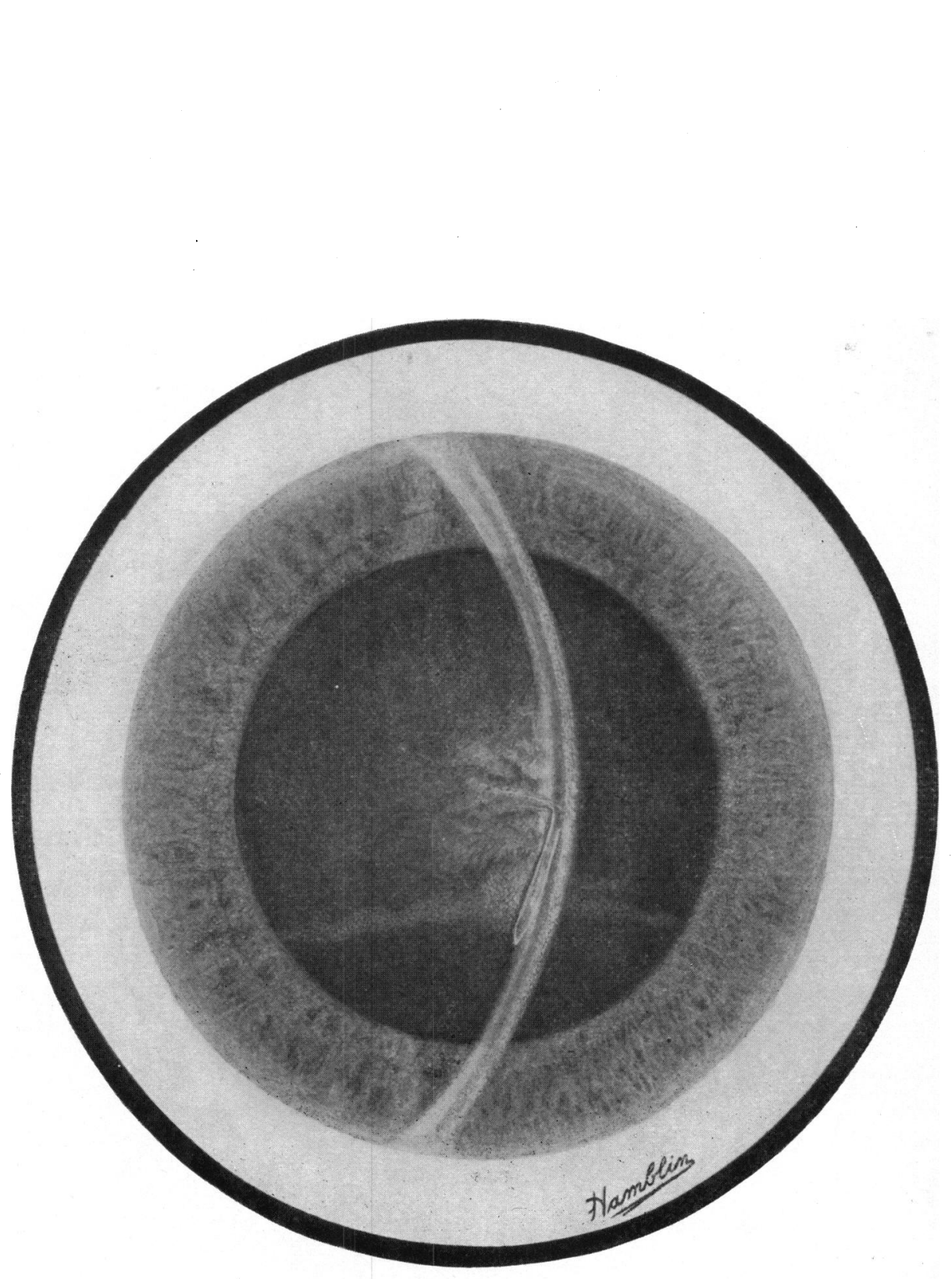


Treatment was continued as before, potassium iodide being given intermittently and by June, 1928 , the left eye could see $6 / 60$ with the old glasses, though it relapsed to less than 6/60 in July. In January of this year, a star-shaped pigmented area had developed in the anterior layers of the cornea and a wrinkle had appeared in Descemet's membrane, the opacity being unchanged. The condition as seen with the slit-lamp is shown in the figure. In June it was thought that an optical iridectomy might be of service, but before doing this, I decided to go thoroughly over the patient's refraction again. To my surprise I found that the left eye with +9.0 D.sph. $+1.0 \mathrm{cyl}$. $60^{\circ}$ read $6 / 12$, and one letter of $6 / 9$-the opacity was by now rather faint, but still clearly visible with the slit-lamp and the change of refraction was evidently due to cicatricial flattening of the cornea following on partial resolution of the opacity.

A rough calculation shows that a diminution of $8 \mathrm{D}$. in the refractive power of the eye could be produced by a flattening of the cornea sufficient to increase the radius of curvature of its anterior surface from the normal $8 \mathrm{~mm}$. to $9.74 \mathrm{~mm}$.

The steps of this calculation are as follows:- the formula connecting refractive index, radius of curvature and focal length is $\mathrm{F}=\frac{\mu \mathrm{R}}{\mu-1}$. In a problem of this kind, where we are concerned only with a small difference, we shall make no serious error if we regard the refraction system of the eye as being homogeneous. We must therefore first determine the value of $\mu$ for an eye, being given that $\mathrm{F}=22.7 \mathrm{~mm}$. (the distance from the anterior surface of the cornea to the macula) and $R=8 \mathrm{~mm}$. - the radius of curvature of the anterior surface of the normal cornea. We thus have 22.7 $=\frac{8 \mu}{\mu-1}$ which gives $\mu=1.54$. A focal length of $22.7 \mathrm{~mm}$. measured from the anterior surface of the cornea is equivalent to 44 dioptres.

The effect of the disease in the cornea was to reduce this by $8 \mathrm{D}$. and to make it 36 D., i.e., $27.78 \mathrm{~mm}$. Again using our formula $\mathrm{F}=\frac{\mu \mathrm{R}}{\mu-1}$ and substituting this value and the value we have already determined for $\mu$ we get $R=9.74 \mathrm{~mm}$.

The patient was examined with a Javal-Schiötz ophthalmometer which gave a difference of 4 dioptres between the two eyes, corresponding to an increase of $1 \mathrm{~mm}$. in the radius of curvature of the cornea. This can be explained by the fact that the image of the mires is formed by the mid-peripheral and not by the pupillary area of the cornea. The opacity was limited to the latter area and the flattening would therefore be most marked in this area also. 
Conclusions:-The interest of the case lies in the following points :-

1. The development of an opacity in the posterior layers of the left cornea unattended by any inflammatory reaction.

2. The restriction of this opacity to the cornea of one eye only; whether this was due to the treatment adopted, it is not, of course, possible to say.

3 . The subsequent development of eight dioptres of hypermetropia, with an alteration of $60^{\circ}$ in the axis of the astigmatism.

\title{
B.WELCHII INFECTION OF GLOBE FOLLOWING PERFORATING INJURY
}

\author{
BY \\ W. E. Heath \\ SENIOR HOUSE SURGEON, ROYAL LONDON OPHTHALMIC HOSPITAL
}

THE following case would appear to be sufficiently rare to justify its publication.

V. E., a labourer, aged 46 years, attended the Royal London Ophthalmic Hospital on May 4, 1929, at 1.30 p.m. He stated that on the previous afternoon he was chipping some concrete with a hammer and chisel when something flew up and struck his left eye. It caused him little trouble at the time, and he continued work. He attended because it still felt as if there was something in his left eye.

On examination the right eye was normal. The left eye was slightly injected, and there was a small perforation of the sclera $3 \mathrm{~mm}$. outside the limbus. The cornea was bright and clear. Several small bubbles of gas were present in the anterior chamber, and during examination a fresh one was seen to come forward through the pupil. The eye was not tender. L.V., shadows.

5.30 p.m. The condition of the left eye was much changed. There was considerable pain in and around the eye. There was much chemosis and the cornea was no longer bright but oedematous and hazy. The anterior chamber was abnormally deep, the globe was very tender, and there was no perception of light in the eye. The patient felt ill, and had a "toxic" appearance. Temperature $98.2^{\circ} \mathrm{F}$., pulse 90 .

8.0 p.m. There was now marked oedema of the left upper lid, greatly increased chemosis, and some proptosis. A large bubble of gas could be seen, distending the anterior chamber and practically filling it. 